\title{
Clinical importance of IL-22 cascade in IBD
}

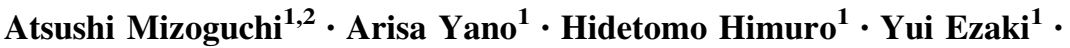 \\ Takayuki Sadanaga ${ }^{1} \cdot$ Emiko Mizoguchi $^{1,2}$
}

Received: 2 October 2017/ Accepted: 4 October 2017/Published online: 26 October 2017

(c) The Author(s) 2017. This article is an open access publication

\begin{abstract}
IL-22 is a relatively new cytokine that is characterized by several unique biological properties. In the intestines, the effect of IL-22 is restricted mainly to nonlymphoid cells such as epithelial cells. Interestingly, the expression pattern and major cellular source of IL-22 have distinct difference between large and small intestines. IL22 possesses an ability to constitutively activate STAT3 for promoting epithelial cell regeneration and reinforcing mucosal barrier integrity through stimulating the expression of anti-bacterial peptide and mucins. Of note, IL-22 is characterized as a two-faced cytokine that can play not only protective but also deleterious roles in the intestinal inflammation depending on the cytokine environment such as the expression levels of IL-23, T-bet, and IL-22 binding protein. Most importantly, clinical relevance of IL-22 to inflammatory bowel disease has been well highlighted. Mucosal healing, which represents the current therapeutic goal for IBD, can be induced by IL-22. Indeed, indigo naturalis, which can activate IL-22 pathway through Ahr, has been shown in a clinical trial to exhibit a strong therapeutic effect on ulcerative colitis. Despite the beneficial effect of IL-22, continuous activation of the IL-22 pathway increases the risk of colitis-associated cancer, particularly in patients with an extended history of IBD. This review article discusses how IL-22 regulates colitis, how beneficial versus deleterious effects of IL-22 is determined, and why IL-22 represents a promising target for IBD therapy.
\end{abstract}

Atsushi Mizoguchi

mizoguchi_atsushi@med.kurume-u.ac.jp

1 Department of Immunology, Kurume University School of Medicine, Asahi-machi, Kurume, Fukuoka 830-0011, Japan

2 IBD Center, Kurume University Hospital, Kurume, Japan
Keywords Ahr · Indigo naturalis · IL-22BP · IL-23 · Mucus

$\begin{array}{ll}\text { Abbreviations } \\ \text { Ahr } & \text { Aryl hydrocarbon receptor } \\ \text { CAC } & \text { Colitis-associated cancer } \\ \text { DC } & \text { Dendritic cells } \\ \text { DSS } & \text { Dextran sulfate sodium } \\ \text { IBD } & \text { Inflammatory bowel disease } \\ \text { IL- } & \text { IL-22 binding protein } \\ \text { 22BP } & \\ \text { ILC } & \text { Innate lymphoid cells } \\ \text { Muc } & \text { Mucin } \\ \text { Reg } & \text { Regenerating gene } \\ \text { ROR } \gamma \text { t } & \text { RAR-related orphan receptor } \gamma \text { t } \\ \text { STAT } & \text { Signal transducers and activator of transcription } \\ \text { TCR } & \text { T cell receptor } \\ \text { UC } & \text { Ulcerative colitis }\end{array}$

\section{Introduction}

Interleukin (IL)-22 is a relatively new cytokine that was discovered in 2000 in both humans and mice [1, 2]. IL-22 was identified in humans as a new ligand of IL-10R2 that can activate STATs 1, 3, and 5 [1] and simultaneously identified in mice as an IL-10-related $\mathrm{T}$ cell-inducible factor that was detected in thymic lymphomas stimulated with IL-9 [2]. Rapid progress in the IL-22 biology has since been made in basic and clinical science, both of which have demonstrated its unique properties [3-6]. For example, expression of IL-22 receptor (IL-22R) is restricted to nonhematopoietic cells such as intestinal and respiratory 
epithelial cells, keratinocytes, and hepatocytes, allowing IL-22 to specifically target innate immune responses without directly affecting adaptive immune cells [7]. Of note, the function of IL-22 has been figuratively called "a sheep in wolf's clothing" [8] or "a two-headed cytokine" [4] due to its dual abilities to not only exacerbate but also improve inflammatory responses. In addition, IL-22 exhibits unique expression pattern particular in the intestine. IL-22 is constitutively expressed in the small intestine to maintain the epithelial integrity that provides the first line of defense against enteric microorganisms for preserving appropriate host-microbial interactions [9, 10]. In contrast, IL-22 represents an inducible cytokine in the large intestine where IL-22 expression is hardly detectable under healthy state and can be induced under inflammatory conditions such as inflammatory bowel disease (IBD) [11-13]. The clinical relevance of IL-22 to IBD has been well highlighted by the fact that the majority of IL-22-associated molecules are encoded by IBD susceptibility genes [3]. In addition, IL-22 signaling may provide a clue to solve a long-standing epidemiologic mystery in IBD regarding a negative association of cigarette smoking with the development of ulcerative colitis (UC).

\section{Distinct IL-22 expression pattern in small versus large intestine}

There are distinct expression patterns of IL-22 between small and large intestines [3]. IL-22 is constitutively expressed in the small intestine of humans and mice to maintain epithelial barrier integrity against enteric microorganisms that play an important role in the pathogenesis of IBD [9, 10, 14]. In contrast, IL-22 expression, which is rarely detectable in the large intestine (colon) of humans and mice under healthy condition [11-13, 15-17], is induced by a wide variety of inflammatory conditions ranging from IBD to infection [11-13, 15-17]. However, the expression level of inducible IL-22 may differ depending on the types of inflammation. For example, the expression level of IL-22 in the inflamed colon is higher in Crohn's disease (CD) patients as compared to UC patients $[11,12,15]$. Similarly, much higher expression level of IL22 has been reported in the inflamed colon of a mouse model of CD (CD45RB model) as compared to a mouse model of UC (TCR $\alpha$ KO mice) [12]. CD is characterized by dominant Th1/Th17 responses, whereas UC is associated with enhanced $\mathrm{Th} 2$ response [18]. In addition, atopic dermatitis, which exhibits a dominant Th2 response, is associated with lower levels of IL-22 expressions as compared to psoriasis characterized by enhanced Th1/Th17 responses [19]. Therefore, it is possible that IL-22 expression, which is elicited by inflammatory insults, is further conditioned by the local cytokine environments (e.g., Th1 versus Th2).

\section{Cellular sources of IL-22 in the intestine}

IL-22 can be expressed by many cell types, including Th17 $\mathrm{CD}^{+} \mathrm{T}$ cells that express both IL-17 and IL-22, Th22 $\mathrm{CD}^{+}{ }^{+} \mathrm{T}$ cells that express IL-22 without producing IL-17, $\mathrm{CD}^{+} \mathrm{T}$ cells, TCR $\gamma \delta \mathrm{T}$ cells, dendritic cells (DCs), neutrophils, NK cells, and group3 innate lymphoid cell (ILC) population including ILC3 and lymphoid tissue inducer (LTi) cells [4-6, 20]. The major cellular source of IL-22 in the small intestine is RAR-related orphan receptor (ROR) $\gamma t$-dependent ILC3 that can develop in the absence of enteric bacteria as indicated by the development of ILC3 in germ-free mice [14, 21]. In Toxoplasma gondii infection, the major source of IL-22 in the small intestine shifts from ILC3 to $\mathrm{CD}^{+}{ }^{+} \mathrm{T}$ cells [22].

In human colon, different types of cells may be responsible for the inflammation-induced production of IL22 depending on the type of inflammation and presumably on the disease stages. The ability of NK cells and Th17 T cells to produce IL-22 was initially reported in the inflamed colon of UC patients [16], and subsequent studies have

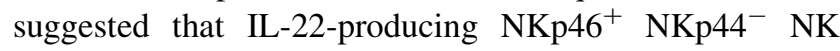
cells more increase in the inflamed colon of $\mathrm{CD}$ patients as compared to that of UC patients [23]. A recent study has found an additional cell type that can be responsible for the production of IL-22 in IBD. CD177 ${ }^{+}$neutrophils produce IL-22 for improving colitis and this neutrophil subset increases in the peripheral blood and inflamed intestine of $\mathrm{UC}$ and $\mathrm{CD}$ patients [20]. In CD patients, $\mathrm{CD} 4^{+} \mathrm{T}$ cells characterized by the expression of natural killer group 2 member D (NKG2D) have been reported to produce IL-22 [24]. Group 3 ILC population is further classified into ILC3 that produces IL-22 and expresses CD56 and LTi cells that produce both IL-17 and IL-22 without expression of CD56 [25]. An increases of both IL-22-producing CD56 ${ }^{+}$ILC3 and IL-17-producing $\mathrm{CD} 56^{-} \mathrm{LTi}$ cells are observed in the inflamed colon of CD patients as compared to UC patients [26]. Alternatively, ILC3 has recently been shown to possess an additional function to serve as immune suppressive antigen presenting cells capable of eliminating enteric bacteria-specific colitogenic $\mathrm{CD}^{+}{ }^{+} \mathrm{T}$ cells through an MHC class II-dependent manner [27]. In the inflamed colon of pediatric CD patients, the total frequency of ILC3 cells is not altered, but their expression level of MHC class II is reduced [28].

Similar to IBD patients, cellular sources of IL-22 vary in the inflamed colon of mouse IBD models depending on the fundamental disease mechanisms. In a mouse model of CD (CD45RB transfer model), both NK cells and Th17 cells are primarily responsible for the production of IL-22 in the 
inflamed colon [13]. Alternatively, dendritic cells (DCs) [17], neutrophils [29], and/or TCR $\gamma \delta$ T cells [30] represent the major source of IL-22 in an acute colonic injury model, which is induced by oral administration of dextran sulfate sodium (DSS). DCs have also been suggested as a major source of IL-22 in C. rodentium- infectious colitis model [31]. In contrast, a study suggested in the $C$. rodentium infectious model that ROR $\gamma \mathrm{t}^{+} \mathrm{LTi}$ cells, but not DCs, produce IL-22 in the inflamed colon [32]. In addition, IL23-dependent LTi cells, which are characterized by the localization within the intraepithelial compartment of colon, have been proposed to represent a dominant source of colonic IL-22 in the context of $C$. rodentium infection [33]. Taken together, these findings indicate that IL-22 can be produced by many cell types depending on the tissue involved and on the healthy versus disease states.

\section{Epithelial cell-specific STAT3 activation by IL-22}

STAT3 is one of the major signaling molecules involved in the pathogenesis of IBD. However, STAT3 possesses dual abilities to not only improve but also exacerbate intestinal inflammation. Activation of STAT3 in adaptive immune cells such as $\mathrm{CD} 4{ }^{+} \mathrm{T}$ cells contributes for the development of colitis in a mouse model of CD [34]. On the other hand, activation of STAT3 in innate immune cells such as macrophages contributes to the suppression of colitis as indicated by the spontaneous development of colitis in a conditional knockout mouse strain in which the stat 3 gene is specifically deleted in macrophages/neutrophils [35]. In addition, absence of STAT3 in epithelial cells makes mice more susceptible to DSS-induced acute colonic injury [17]. Therefore, to pay careful attention would be needed when STAT3 is considered as a target for the treatment of IBD.

IL-22 activates (phosphorylates) STAT3, to a lesser extent STAT1, and in certain cells STAT5 $[36,37]$. This STAT3 activation is mediated by tyrosine kinase 2 (Tyk2) [38]. In addition, IL-22 has been reported to activate Erk1/ 2, JNK, and p38 MAP in some, not all, epithelial cell lines. A high dose of IL-22 activates Erk1/2, JNK, and p38 MAP kinase in a rat hepatoma cell line [36, 37] and human colonic cancer cell line HT29 [15]. In contrast, inability of IL-22 to activate Erk/1/2 has been shown in a human hepatoma cell line HepG2 [39] and primary epithelial cells isolated freshly from human and mouse colons [12]. IL-22 binds to a heterodimeric receptor composed of IL-22R1 and IL-10R2 [4-6]. IL-10R2 is ubiquitously expressed by majority of cell types, while the expression of IL-22R1 is restricted to non-hematopoietic cells such as epithelial cells, hepatocytes, and keratinocytes [4-6]. This expression pattern of IL-22R1 allows IL-22 to activate STAT3 specifically in intestinal epithelial cells [7]. Indeed, epithelial STAT3 activation induced by intestinal damage has been demonstrated to depend more on IL-22 rather than IL-6, a well-known activator of STAT3 [17]. This strong activation of STAT3 by IL-22 may be explained by the ability of IL-22R1 to constitutively, not transiently, activate STAT3 through constitutive interaction of its $\mathrm{C}$-terminal tail with the coiled-coil domain of STAT3 [40].

\section{Production of anti-bacterial peptides by IL-22}

Dysregulated host-microbial interactions are closely involved in the pathogenesis of IBD. Epithelial cells provide the first barrier against enteric microorganisms, and the ability of IL-22 to reinforce the epithelial barrier integrity has been well documented [3]. IL-22 stimulates the production of different kinds of anti-bacterial peptides such as S100A7, S100A8, S100A9 $\beta$-defensin 2, and regenerating gene (Reg) III $\gamma$ and RegIII $\beta$ [17, 31, 41-43]. One of well-studied anti-bacterial peptides in the field of IL-22 may be RegIII family. Bactericidal ability of RegIII $\gamma$ against Gram-positive bacteria [44] was first discovered in 2006, and a subsequent study using RegIII $\alpha$ identified that the bactericidal effect is mediated by the formation of a hexameric membrane-permeabilizing oligomeric pore on Gram-positive bacteria and the bactericidal effect is inhibited by Gram-negative bacteria-derived lipopolysaccharide [45]. Alternatively, a protective role of RegIII $\gamma$ and RegIII $\beta$ against Gram-negative bacteria $C$. rodentium has also been proposed [31]. There still remains an issue under debate regarding whether RegIII expression is mediated directly by IL-22-dependent STAT3 activation or not. Several investigators suggested the induction of RegIII $\gamma$ and $\beta$ expressions through IL-22-dependent STAT3 activation [17], whereas others suggested the NFKB1-dependent RegIII $\gamma$ expression through IL-23 or MyD88 [46, 47]. A recent study has brought an attractive new concept that RegIII $\beta$ represents the initiation, rather than downstream, molecule in IL-22 pathway. RegIII $\beta$ is, at first, produced by epithelial cells through IL-23 receptor signaling, and the epithelial-derived RegIII $\beta$ then recruits IL-22-producing neutrophils that contribute for the improvement of colitis [48].

Other IL-22-associated anti-bacterial peptides that have clinical relevance may be S100A8 and S100A9. S100A8 and S100A9 form a heterodimer complex termed calprotectin, and fecal calprotectin has been widely used as a biomarker for IBD [49]. Although calprotectin is produced mainly by neutrophils, inflammation can induce the ectopic expression of calprotectin in colonic epithelial cells by IL22 [42]. In addition, expressions of S100A8 and S100A9 are mediated by STAT3 activation [50]. Therefore, it is possible that the fecal calprotectin may reflect not only neutrophil-derived calprotectin but also ectopically 
expressed calprotectin in epithelial cells by inflammationinduced IL-22.

\section{Reinforcement of mucus barrier integrity by IL-22}

Mucus, which covers the intestinal surface, also plays a major role in preserving epithelial barrier integrity [51]. The mucus layer in the colon is composed of outer and inner stratum; the outer is a loose gel layer where it is unattached to the epithelial surface and provides a place for colonized bacteria, whereas the inner stratum is a firm mucus layer that is directly attached to the epithelial surface to prevent bacterial intrusion [52]. Mucin (Muc) 1, which is a membrane-bound mucin, represents one of the major components in the intestinal mucus [51]. A protective role of Muc1 in mouse models of UC and CD has been demonstrated [53]. The ability of IL-22 to promote the production of functional Muc1 through activation of STAT3 has been demonstrated using human colonic cancer cell lines (T84 and HT29) and primary colonic epithelial cells from mice $[12,54]$. Consistent with these findings, STAT3 has been demonstrated to bind within the promoter region of the mucl gene [55]. These findings from in vitro and mouse studies are further supported by data from IBD patients. An early onset IBD patient who has no functional IL-10R2 (a receptor of IL-22) due to polymorphism within illorb gene has been reported to lack Muc1 expression [56]. Importantly, Muc1 is a heavily glycosylated protein with over $80 \%$ (per total molecular weight) of carbohydrates that are required to form a viscous firm barrier. Therefore, not only the expression of Muc1 but also its complete glycosylation are required to preserve epithelial barrier integrity. Indeed, overexpression of hypoglycosylated Muc1 makes breaches in the mucus barrier [57] and exacerbates colitis [58]. Of note, IL-22 has been demonstrated to promote glycosylation [43, 59]. Therefore, it is possible that the dual abilities to stimulate not only Muc1 expression but also glycosylation allow IL-22 to produce completely firm inner mucus layer to prevent bacterial invasion.

\section{Mucosal healing by IL-22}

IL-22-dependent activation of STAT3 enhances the transcription of anti-apoptotic and pro-proliferative genes such as birc5, pla2g5, smo, myc, mclland regI $\alpha[16,60]$. The expression of deleted in malignant brain tumor 1 (DMBT1), which may play a role in epithelial cell differentiation, is also induced by IL-22 [61]). These abilities allow IL-22 to promote mucosal healing by stimulating epithelial cell regeneration with goblet cell restitution $[12,17]$. In addition, recent studies have demonstrated that the epithelial cell regeneration is initiated by activation of intestinal stem cells through IL-22-dependent activation of STAT3 but not STAT1 [62, 63].

Consistent with these basic observations, the ability of IL-22 to promote mucosal healing has been well documented in vivo by using different experimental approaches. Mucosal healing after epithelial damage induced by DSS was impaired in IL-22-deficient mice [17], IL-23R-deficient mice that lack IL-22 expressions [47], and WT mice treated with neutralizing anti-IL-22 Abs [12]. In addition, a gene therapy to enhance colonic IL-22 expression [12] and an antibody-based targeted delivery of IL-22 to inflamed area [64] promoted the mucosal healing. The mucosal healing was also enhanced by the treatment with Ficz, which is a ligand of Ahr capable of inducing the expression of IL-22 [65]. Since the induction and maintenance of mucosal healing is the major therapeutic goal in the management of IBD [66], the ability to promote mucosal healing clearly highlights the relevance of IL-22 for IBD therapy.

\section{Newly identified functions of IL-22}

Attractive new functions of IL-22 to induce diarrhea for the clearance of enteric pathogens, to dampen adaptive immune responses against enteric bacterial antigens, and to improve endoplasmic reticulum (ER) stress have recently been demonstrated. IL-22 stimulated the expression of a tight junction molecule Claudin-2, which induces water efflux (diarrhea) for the clearance of enteric pathogens [67]. In addition, IL-22 suppressed the antigen uptake of follicular associated epithelium (FAE) that covers Peyer's and colonic patches where they provide a place for the induction of adaptive immune responses against enteric antigens [68]. Furthermore, IL-22 was shown to reduce epithelial ER/oxidative stress induced by high-fat diets [69].

\section{Dual roles of IL-22 in intestinal inflammation}

As referred to as "a sheep in wolf's clothing" [8] or "a two-headed cytokine" [4], not only protective but also deleterious roles of IL-22 have been reported in intestinal inflammation models [3]. In infectious models, IL-22-deficient mice are highly susceptible to intestinal inflammation caused by Citrobacter rodentium [14, 31, 33, 70], Salmonella enterica [71], and candidiasis [72]. In contrast, Toxoplasma gondii-induced immunopathology was improved in the absence of IL-22 [22].

Although the involvement of IL-22 in mucosal healing has been reported reproducibly by many groups, the different roles of IL-22 have been demonstrated in chronic colitis models. In a Th2-mediated chronic colitis model (TCR $\alpha \mathrm{KO}$ mice) representing $\mathrm{UC}, \mathrm{IL}-22$ was shown to 
play a protective role by reinforcing intestinal mucus barrier function [12]. In a Th1-mediated CD model (CD45RB model) that is induced by the adoptive transfer of naïve $\mathrm{CD}^{+}{ }^{+} \mathrm{T}$ cells into a immune-deficient host, both $\mathrm{T}$ cellderived and NK cell-derived IL-22 contributed for the suppression of colitis [13]. Ficz, which is a ligand of Ahr capable of inducing IL-22 expression, was reported to improve the colitis of the CD45RB model as well as acute CD model induced by intrarectal administration of trinitrobenzene sulfonic acid (TNBS) [65]. Alternatively, in a chronic colitis model that is induced by the adoptive transfer of memory $\mathrm{CD} 4^{+} \mathrm{T}$ cells, a proinflammatory role of memory T cell-derived IL-22 was proposed [73]. Similarly, IL-23R-dependent IL-22 production caused intestinal inflammation in an innate colitis model that was induced in immune-deficient mice by administration of anti-CD40 mAbs [74].

\section{Control of IL-22 functions by IL-23R and T-bet}

It's becoming increasingly apparent that the function of IL22 is positively and negatively regulated by the complicated interactions with other factors (Fig. 1). One of the nice examples may be psoriasis, in which the pathogenic potential of IL-22 is elicited only in the presence of IL-17 and IFN- $\gamma$ [75]. Similarly, IL-22 plays a pro-inflammatory role in the presence of IL-17A and conversely plays a protective role in the absence of IL-17A in bleomycininduced airway inflammation [76]. In an IBD model, IL-22 plays a pathogenic role under a condition where $\mathrm{T}$ cells are hyper responsive to IL-23 for their Th17 differentiation due to absence of T-bet (a transcription factor for Th1 differentiation) [77]. Alternatively, early induction of IL-23 and IL-1 $\beta$, although both are pro-inflammatory cytokines, are required for initiating the IL-22-dependent tissue repair [78]. In addition, IL-23 signaling in epithelial cells licenses the protective effect of IL-22 on intestinal inflammation. IL-23R-mediated signaling stimulates epithelial cells to produce RegIII $\beta$, which then recruits IL-22-producing neutrophils capable of improving colitis [48]. Interestingly, an autocrine regulation of IL-22 pathway has also been proposed recently. The RegIII $\beta$ produced by epithelial cells, in turn, inhibits their STAT3 activation in response to IL-22 [79].

\section{An endogenous inhibitor of IL-22}

Activation of IL-22 is tightly and directly regulated by an endogenous inhibitor. IL-22 binds to not only a heterodimeric receptor composed of IL-10R2 and IL-22R1 but also a soluble class II cytokine receptor designated IL22Ra2 (also called IL-22 binding protein, IL-22BP, or CRF2-10). In comparison with IL-22R1, IL-22BP has
20-1000 fold higher affinity to IL-22 [80-82]. Therefore, IL-22BP can strongly inhibit the biological activity of IL22 in vitro and in vivo by competing with IL-22R1/IL-22 interaction [12, 80-82]. IL-22BP is highly expressed in placenta, spleen, skin, and lung, and to a lesser extent in large and small intestine of humans [80]. In mouse intestine, DCs [83], $\mathrm{CD}^{+}{ }^{+} \mathrm{T}$ cells [84], and epithelial cells [85] have been proposed as a producer of IL-22BP. The IL22BP is highly expressed in the normal colon and significantly reduced during acute inflammation induced by DSS $[12,83,86]$. The inflammation-induced reduction of IL22BP expression is caused by a formation of inflammasomes that function as a sensor of stress to activate IL-1 and IL-18 [83] or by the maturation of DCs, suggesting immature DCs as a source of IL-22BP [86]. In contrast to mice, rather increased expression of intestinal IL-22BP was observed in patients with IBD, and $\mathrm{CD} 4^{+} \mathrm{T}$ cells [84] and eosinophils [87] have been proposed as the cellular source of IL-22BP. However, more caution may be necessary to evaluate the expression of functional IL-22BP, because there are three functionally different isoforms of IL-22BP in humans but not mice [88]. Isoform 1, which is composed of six exons, is non-functional due to the lack of secretion. Isoform 2, lacking exon 3, represents a homologue of mouse IL-22BP and possesses a strong inhibitory effect on IL-22 activity. Isoform 3, which lacks exons 3 and 5 and partially exon 6 , is most abundantly distributed, but the affinity of isoform 3 to IL-22 is 27 -folds lower than that of isoform 2 [88].

Since IL-22BP expression became rarely detectable during the acute inflammatory response induced by DSS [12, 83], deficiency of IL-22BP in mice had no significant alteration on the acute inflammation [83]. Alternatively, supplementation of IL-22BP expression delayed the recovery from this acute inflammation by inhibiting IL-22 activity [12]. In a chronic colitis model, $\mathrm{TNF}-\alpha$ stimulated the IL-22BP expression in $\mathrm{CD} 4^{+} \mathrm{T}$ cells, leading to the suppression of IL-22-dependent mucosal healing [84]. Indeed, anti-TNF- $\alpha$ treatment reduced the expression of IL-22BP in $\mathrm{CD}^{+}{ }^{+} \mathrm{T}$ cells of IBD patients [84]. Therefore, this finding may provide a clue to further understand the therapeutic mechanism of anti- TNF- $\alpha$ therapy.

\section{IL-22-associated IBD susceptibility gene network}

Several facts have highlighted the clinical significance of IL-22 to IBD. One of the examples is that the majority of IL-22-associated molecules are encoded by IBD susceptibility genes. IL-23 is a heterodimeric cytokine composed of p40 and p19 subunits. The interaction of IL-23 with IL-23R has been demonstrated to not only stimulate IL-22 expression [5, 6], but also positively and negatively control 


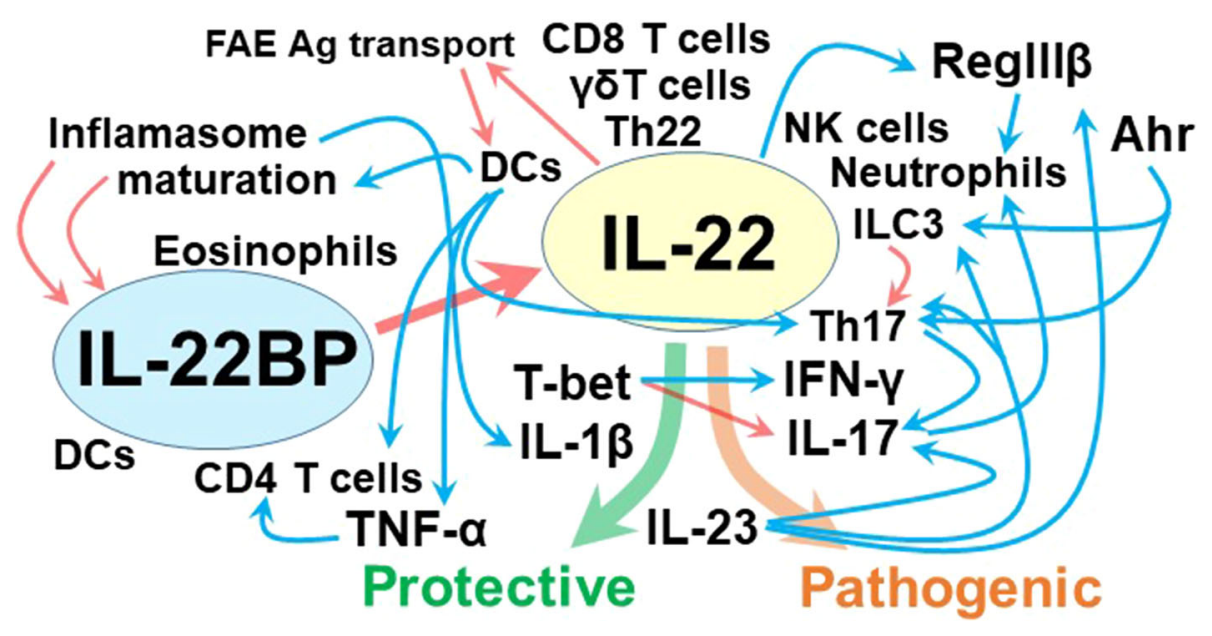

Fig. 1 Regulation of IL-22 functions: IL-22 can be produced by many cell types. The production of IL-22 is stimulated by Ahr, and $\operatorname{RegIII} \beta$ may have the ability to recruit IL-22-producing neutrophils. IL-22 then plays not only protective but also deleterious roles in intestinal inflammation depending on the cytokine environments. IL$1 \beta$ and IL-23-medicated activation of epithelial cells may elicit the beneficial effect of IL-22, whereas hyper response of T cells to IL-23

the function of IL-22 [77, 78]. Il23r gene represents one of the major IBD susceptibility genes and the polymorphism was negatively associated with the development of both CD and UC $[89,90]$. In addition, $p 40$ polymorphism was also associated with the development of CD [91].

The receptor of IL-22 is composed of IL-10R $\beta$ and IL22R1 subunits. Positive association of illorb polymorphisms with CD and UC particularly with early onset of IBD has been well documented [92]. In addition, the il22 gene is located within a UC-risk locus on chromosome $12 \mathrm{q} 15$ [93], and il22 polymorphism in UC patients has been reported in the Chinese [94], but not Mexican [95], population. The ligation of IL-22 receptor is well known to induce the activation of STAT3 through JAK2 and TYK2. The stat $3, j a k 2$, and tyk2 all represent well-defined susceptibility genes for CD and to lesser extent UC [89, 90]. The STAT3 activation then stimulates the colonic epithelial cells to produce Muc1 and Muc13 for barrier reinforcement $[11,12,55]$. The mucl3 gene is an IBD susceptibility gene, and the $m и с l$ gene has been proposed as a candidate susceptible gene of $\mathrm{CD}$ [96]. In addition, the ability of IL-22 to directly or indirectly promote the expressions of fut2, secl, bcl2115, ptpn22, prdml, xbpl, nuprl, erbp3, efemp2, chacl, pbbp, cxcl5, and sk9a3 has recently been demonstrated by a study using IL-22Ra1deficient mice [43]. Importantly, all of them have been reported as IBD susceptibility genes. Taken together, these findings highlight the close involvement of IL-22 in the molecular network associated with IBD susceptibility genes. for acquiring their ability to produce both IL-17 and IFN- $\gamma$ may elicit the deleterious function of IL-22. The activity of IL-22 can be suppressed by an endogenous inhibitor IL-22BP that is produced by DCs, eosinophils, and CD4 ${ }^{+} \mathrm{T}$ cells. TNF- $\alpha$ stimulates the expression of IL-22BP in $\mathrm{CD}^{+} \mathrm{T}$ cells. Alternatively, formation of inflammasome and maturation of DCc may contribute for reducing the IL22BP expression

\section{A clue to resolve an etiological mystery in UC}

A negative association of cigarette smoking with the development UC has been well documented [97]. However, the mechanism is a long-standing question, thus considered as one of ten remaining mysteries in IBD [98]. Aryl hydrocarbon receptor (Ahr), which serves as a sensor that can be activated by a large variety of environmental toxins, can induce the production of IL-22 [99]. Indeed, like IL-22, the beneficial effect of Ahr activation on experimental colitis has been demonstrated [65]. Cigarette smoke contains more than 150 toxins, including dioxin such as 2,3,7,8-tetrachlorodibenzo- $p$-doxin (TCDD) and environmental pollutants such as polycyclic aryl hydrocarbons, of which benzo $[\alpha]$ pyrene $(\mathrm{BaP})$ is a prototype [100]. Of note, TCDD and BaP can activate the Ahr [100], and induction of IL-22 expression by cigarette smoke has recently been demonstrated [101]. These findings may raise an attractive hypothesis that the preventive effect of smoking on UC development is mediated by Ahr-dependent activation of IL-22 pathway.

\section{Therapeutic application of IL-22}

Lactobacilli species metabolize tryptophan to indole-3acetic acid that can activate Ahr for stimulating IL-22 production [102]. Therapeutic benefit of tryptophan on experimental colitis through activation of the IL-22 pathway has also been demonstrated [102, 103]. In addition, the fecal from UC and CD patients was characterized by a low level of tryptophan and indole-3-acetic acid [103]. 
Fig. 2 Clinical importance of IL-22 to IBD particularly UC: The clinical relevance of IL-22 can be highlighted by much basic and clinical evidence. For example, IL-22 can promote the mucosal healing in mice, which is a current major goal of IBD therapy. The majority of molecules induced by IL-22 are encoded by IBD susceptibility genes. In addition, IL-22 stimulates the production of calprotectin, which is a useful biomarker of IBD. Interestingly, the IL-22 pathway may provide a clue to resolve a long-standing etiological mystery that cigarette smoking is negatively associated with the development of UC and to further understand the carcinogenesis pathway of colitis-associated cancer. Importantly, a recent pilot study demonstrated the therapeutic effect of Ahr-activation capable of stimulating IL-22 production of mild-to-moderate UC

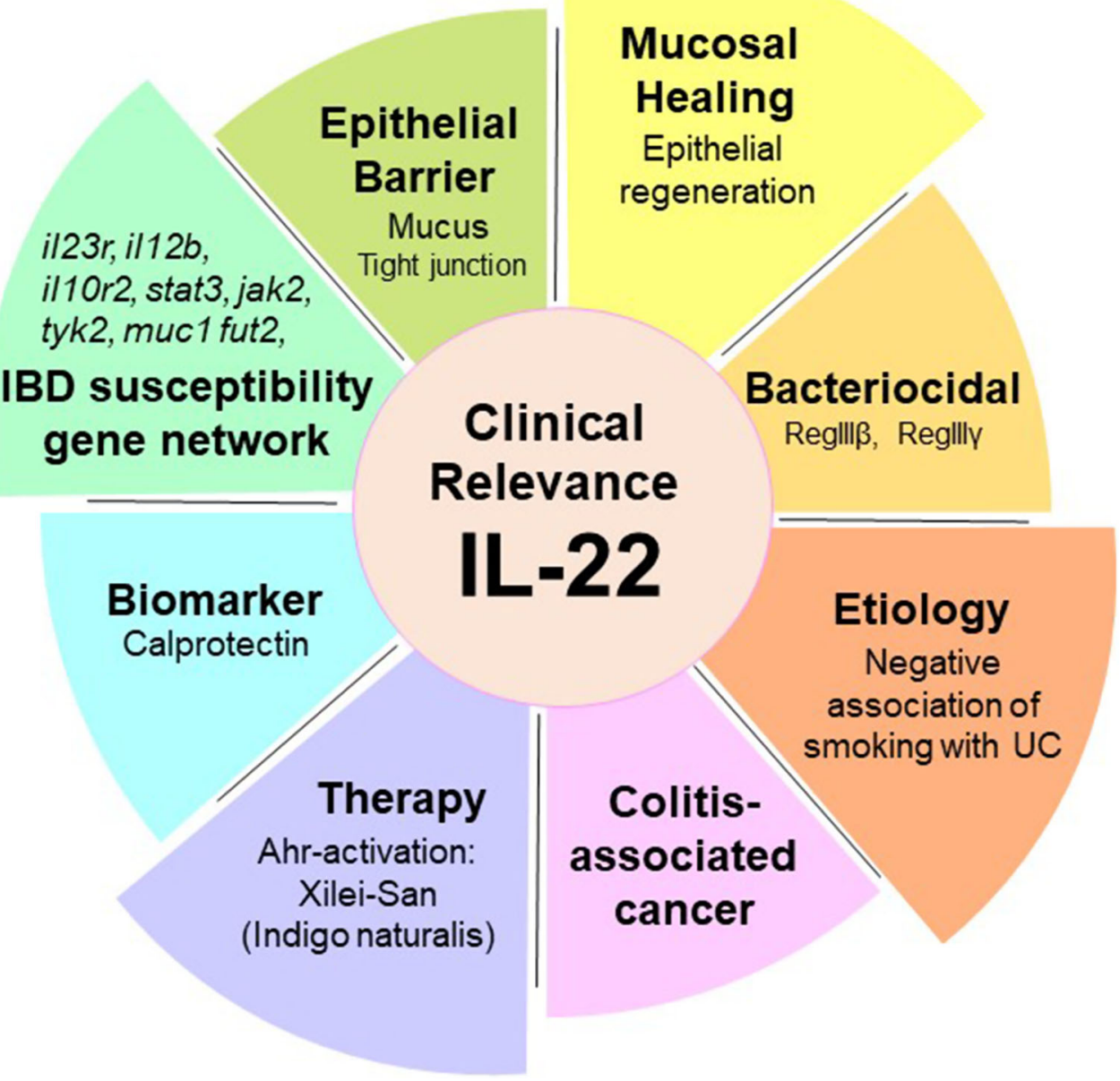

Xilei-San is a Chinese herbal medicine that has been used for the treatment of UC [104]. Xilei-San contains a high concentration of indigo naturalis, a dye extracted from plants. A recent open-label, prospective pilot study on 20 patients with moderate UC showed that oral administration of indigo naturalis induced mucosal healing in $61 \%$ of patients at 8 weeks [105]. Importantly, indigo naturalis is one of the ligands of $\mathrm{Ahr}$, and a recent study in mice demonstrates that the therapeutic effect of indigo naturalis is mediated by Ahr-dependent activation of IL-22 pathway [106]. In addition, the therapeutic potential of other Ahr ligands such as Ficz [65] and ABX464 (the first-in-class anti-HIV drug candidate) [107] against experimental colitis has been reported. These findings clearly highlight the activation of IL-22 as a promising therapeutic measure for IBD, particularly UC. However, more caution may be needed when supplementation of IL-22 is considered for IBD therapy. Chronic inflammation predisposes IBD patients to the risk of colitis-associated cancer that develops through a complex multi-step and multi-factorial processes termed "inflammation-dysplasia-carcinoma sequence" [108]. Hyper activation of STAT3 is one of factors involved in the development of CAC [109], and continuous activation of IL-22 due to lack of IL-22BP has been shown to increase the susceptibility to CAC induced by chronic intestinal inflammation plus a carcinogen AOM [83]. These findings suggest that IL-22/IL-22BP axis critically regulates mucosal healing and tumorigenesis.

\section{Conclusions}

IL-22 is characterized by numerous clinical relevance to IBD (Fig. 2), including the ability to induce the mucosal healing that represents the current therapeutic goal of IBD, the close involvement in IBD susceptibility gene networks, and the association with $\mathrm{CAC}$, the potential role in an etiological mystery of UC, and the stimulation of expression of a biomarker for IBD. In addition, the IL-22 pathway seems to mediate the therapeutic effect of indigo naturalis and partially of anti-TNF $\alpha$ therapy, both of which have been used for the treatment of IBD. Although much more extensive works still need to fully dissect out the mechanism that determines the beneficial versus deleterious 
effect of IL-22 on colitis and that stimulates the tumorigenesis pathway, IL-22 activation would be considered to be a promising therapeutic measures for IBD.

Acknowledgements We would like to greatly thank Ms. Satomi Uchida for her excellent editorial assistance. This project was supported by NIH R01 DK091247 (AM and EM) and by Grants-in-Aid for Scientific Research (B) $15 \mathrm{H} 04813$.

\section{Compliance with ethical standards}

Conflict of interest The authors declare that they have no conflict of interest.

Open Access This article is distributed under the terms of the Creative Commons Attribution 4.0 International License (http://crea tivecommons.org/licenses/by/4.0/), which permits unrestricted use, distribution, and reproduction in any medium, provided you give appropriate credit to the original author(s) and the source, provide a link to the Creative Commons license, and indicate if changes were made.

\section{References}

1. Xie MH, Aggarwal S, Ho WH, et al. Interleukin (IL)-22, a novel human cytokine that signals through the interferon receptor-related proteins CRF2-4 and IL-22R. J Biol Chem. 2000;275:31335-9.

2. Dumoutier L, Louahed J, Renauld JC. Cloning and characterization of IL-10-related T cell-derived inducible factor (IL-TIF), a novel cytokine structurally related to IL-10 and inducible by IL-9. J Immunol. 2000;164:1814-9.

3. Mizoguchi A. Healing of intestinal inflammation by IL-22. Inflamm Bowel Dis. 2012;18:1777-84.

4. Seiderer J, Brand S. IL-22: a two-headed cytokine in IBD? Inflamm Bowel Dis. 2009;15:473-4.

5. Ouyang W, Rutz S, Crellin NK, et al. Regulation and functions of the IL-10 family of cytokines in inflammation and disease. Annu Rev Immunol. 2011;29:71-109.

6. Sonnenberg GF, Fouser LA, Artis D. Border patrol: regulation of immunity, inflammation and tissue homeostasis at barrier surfaces by IL-22. Nat Immunol. 2011;12:383-90.

7. Wolk K, Kunz S, Witte E, et al. IL-22 increases the innate immunity of tissues. Immunity. 2004;21:241-54.

8. Laurence A, O'Shea JJ, Watford WT. Interleukin-22: a sheep in wolf's clothing. Nat Med. 2008;14:247-9.

9. Sanos SL, Bui VL, Mortha A, et al. RORgammat and commensal microflora are required for the differentiation of mucosal interleukin 22-producing NKp46+ cells. Nat Immunol. 2009;10:83-91.

10. Cella M, Fuchs A, Vermi W, et al. A human natural killer cell subset provides an innate source of IL-22 for mucosal immunity. Nature. 2009;457:722-5.

11. Andoh A, Zhang Z, Inatomi O, et al. Interleukin-22, a member of the IL-10 subfamily, induces inflammatory responses in colonic subepithelial myofibroblasts. Gastroenterology. 2005;129:969-84.

12. Sugimoto K, Ogawa A, Mizoguchi E, et al. IL-22 ameliorates intestinal inflammation in a mouse model of ulcerative colitis. J Clin Invest. 2008;118:534-44.

13. Zenewicz LA, Yancopoulos GD, Valenzuela DM, et al. Innate and adaptive interleukin-22 protects mice from inflammatory bowel disease. Immunity. 2008;29:947-57.
14. Lee JS, Cella M, McDonald KG, et al. AHR drives the development of gut ILC22 cells and postnatal lymphoid tissues via pathways dependent on and independent of Notch. Nat Immunol. 2011;13:144-51.

15. Brand S, Beigel F, Olszak T, et al. IL-22 is increased in active Crohn's disease and promotes proinflammatory gene expression and intestinal epithelial cell migration. Am J Physiol Gastrointest Liver Physiol. 2006;290:G827-38.

16. Sekikawa A, Fukui H, Suzuki K, et al. Involvement of the IL-22/ REG Ialpha axis in ulcerative colitis. Lab Invest. 2010;90:496-505.

17. Pickert G, Neufert C, Leppkes M, et al. STAT3 links IL-22 signaling in intestinal epithelial cells to mucosal wound healing. J Exp Med. 2009;206:1465-72.

18. Xavier RJ, Podolsky DK. Unravelling the pathogenesis of inflammatory bowel disease. Nature. 2007;448:427-34.

19. Guttman-Yassky E, Lowes MA, Fuentes-Duculan J, et al. Low expression of the IL-23/Th17 pathway in atopic dermatitis compared to psoriasis. J Immunol. 2008;181:7420-7.

20. Zhou G, Yu L, Fang L,et al. CD177+ neutrophils as functionally activated neutrophils negatively regulate IBD. Gut. 2017. PMID:28468761 (In Press)

21. Sawa S, Cherrier M, Lochner M, et al. Lineage relationship analysis of RORgammat + innate lymphoid cells. Science. 2010;330:665-9.

22. Muñoz M, Heimesaat MM, Danker K, et al. Interleukin (IL)-23 mediates Toxoplasma gondii-induced immunopathology in the gut via matrixmetalloproteinase- 2 and IL-22 but independent of IL-17. J Exp Med. 2009;206:3047-59.

23. Takayama $\mathrm{T}$, Kamada $\mathrm{N}$, Chinen $\mathrm{H}$, et al. Imbalance of NKp44(+)NKp46(-) and NKp44(-)NKp46(+) natural killer cells in the intestinal mucosa of patients with Crohn's disease. Gastroenterology. 2010;139:882-92.

24. Pariente B, Mocan I, Camus M, et al. Activation of the receptor NKG2D leads to production of Th17 cytokines in $\mathrm{CD} 4^{+} \mathrm{T}$ cells of patients with Crohn's disease. Gastroenterology. 2011;141:217-26.

25. Walker JA, Barlow JL, McKenzie AN. Innate lymphoid cellshow did we miss them? Nat Rev Immunol. 2013;13:75-87.

26. Geremia A, Arancibia-Cárcamo CV, Fleming MP, et al. IL-23responsive innate lymphoid cells are increased in inflammatory bowel disease. J Exp Med. 2011;208:1127-33.

27. Hepworth MR, Monticelli LA, Fung TC, et al. Innate lymphoid cells regulate $\mathrm{CD}^{+}{ }^{+} \mathrm{T}$-cell responses to intestinal commensal bacteria. Nature. 2013;498:113-7.

28. Hepworth MR, Fung TC, Masur SH, et al. Immune tolerance. Group 3 innate lymphoid cells mediate intestinal selection of commensal bacteria-specific $\mathrm{CD}^{+} \mathrm{T}$ cells. Science. 2015;348:1031-5.

29. Zindl CL, Lai JF, Lee YK, et al. IL-22-producing neutrophils contribute to antimicrobial defense and restitution of colonic epithelial integrity during colitis. Proc Natl Acad Sci USA. 2013;110:12768-73.

30. Mielke LA, Jones SA, Raverdeau M, et al. Retinoic acid expression associates with enhanced IL-22 production by $\gamma \delta \mathrm{T}$ cells and innate lymphoid cells and attenuation of intestinal inflammation. J Exp Med. 2013;210:1117-24.

31. Zheng Y, Valdez PA, Danilenko DM, et al. Interleukin-22 mediates early host defense against attaching and effacing bacterial pathogens. Nat Med. 2008;14:282-9.

32. Tumanov AV, Koroleva EP, Guo X, et al. Lymphotoxin controls the IL-22 protection pathway in gut innate lymphoid cells during mucosal pathogen challenge. Cell Host Microbe. 2011;10:44-53. 
33. Sonnenberg GF, Monticelli LA, Elloso MM, et al. CD4(+) lymphoid tissue-inducer cells promote innate immunity in the gut. Immunity. 2011;34:122-34.

34. Durant L, Watford WT, Ramos HL, et al. Diverse targets of the transcription factor STAT3 contribute to T cell pathogenicity and homeostasis. Immunity. 2010;32:605-15.

35. Takeda K, Clausen BE, Kaisho T, et al. Enhanced Th1 activity and development of chronic enterocolitis in mice devoid of Stat3 in macrophages and neutrophils. Immunity. 1999;10:39-49.

36. Pestka S, Krause CD, Sarkar D, et al. Interleukin-10 and related cytokines and receptors. Annu Rev Immunol. 2004;22:929-79.

37. Nagalakshmi ML, Rascle A, Zurawski S, et al. Interleukin-22 activates STAT3 and induces IL-10 by colon epithelial cells. Int Immunopharmacol. 2004;4:679-91.

38. Hainzl E, Stockinger S, Rauch I, et al. Intestinal epithelial cell tyrosine kinase 2 transduces IL-22 signals to protect from acute colitis. J Immunol. 2015;195:5011-24.

39. Wolk K, Witte E, Hoffmann U, et al. IL-22 induces lipopolysaccharide-binding protein in hepatocytes: a potential systemic role of IL-22 in Crohn's disease. J Immunol. 2007;178:5973-81.

40. Dumoutier L, de Meester C, Tavernier J, et al. New activation modus of STAT3: a tyrosine-less region of the interleukin-22 receptor recruits STAT3 by interacting with its coiled-coil domain. J Biol Chem. 2009;284:26377-84.

41. Wolk K, Witte E, Wallace E, et al. IL-22 regulates the expression of genes responsible for antimicrobial defense, cellular differentiation, and mobility in keratinocytes: a potential role in psoriasis. Eur J Immunol. 2006;36:1309-23.

42. Liang SC, Tan XY, Luxenberg DP, et al. Interleukin (IL)-22 and IL-17 are coexpressed by Th17 cells and cooperatively enhance expression of antimicrobial peptides. $\mathrm{J}$ Exp Med. 2006;203:2271-9.

43. Pham TA, Clare S, Goulding D, et al. Epithelial IL-22RA1mediated fucosylation promotes intestinal colonization resistance to an opportunistic pathogen. Cell Host Microbe. 2014;16:504-16.

44. Cash HL, Whitham CV, Behrendt CL, et al. Symbiotic bacteria direct expression of an intestinal bactericidal lectin. Science. 2006;313:1126-30.

45. Mukherjee S, Zheng H, Derebe MG, et al. Antibacterial membrane attack by a pore-forming intestinal C-type lectin. Nature. 2014;505:103-7.

46. Brandl K, Plitas G, Schnabl B, et al. MyD88-mediated signals induce the bactericidal lectin RegIII gamma and protect mice against intestinal Listeria monocytogenes infection. J Exp Med. 2007;204:1891-900.

47. Cox JH, Kljavin NM, Ota N, et al. Opposing consequences of IL-23 signaling mediated by innate and adaptive cells in chemically induced colitis in mice. Mucosal Immunol. 2012;5:99-109.

48. Aden K, Rehman A, Falk-Paulsen M, et al. Epithelial IL-23R signaling licenses protective IL-22 responses in intestinal inflammation. Cell Rep. 2016;16:2208-18.

49. Ikhtaire S, Shajib MS, Reinisch W, et al. Fecal calprotectin: its scope and utility in the management of inflammatory bowel disease. J Gastroenterol. 2016;51:434-46.

50. Lapeire L, Hendrix A, Lambein K, et al. Cancer-associated adipose tissue promotes breast cancer progression by paracrine oncostatin $M$ and Jak/STAT3 signaling. Cancer Res. 2014;74:6806-19.

51. Hattrup CL, Gendler SJ. Structure and function of the cell surface (tethered) mucins. Annu Rev Physiol. 2008;70:431-57.

52. Johansson ME, Sjövall H, Hansson GC. The gastrointestinal mucus system in health and disease. Nat Rev Gastroenterol Hepatol. 2013;10:352-61.
53. Nishida A, Lau CW, Zhang M, et al. The membrane-bound mucin muc1 regulates Th17-cell responses and colitis in mice. Gastroenterology. 2012;142:865-74.

54. Andoh A, Shioya M, Nishida A, et al. Expression of IL-24, an activator of the JAK1/STAT3/SOCS3 cascade, is enhanced in inflammatory bowel disease. J Immunol. 2009;183:687-95.

55. Yuan ZL, Guan YJ, Wang L, et al. Central role of the threonine residue within the $p+1$ loop of receptor tyrosine kinase in STAT3 constitutive phosphorylation in metastatic cancer cells. Mol Cell Biol. 2004;24:9390-400.

56. Begue B, Verdier J, Rieux-Laucat F, et al. Defective IL10 signaling defining a subgroup of patients with inflammatory bowel disease. Am J Gastroenterol. 2011;106:1544-55.

57. Kadayakkara DK, Beatty PL, Turner MS, et al. Inflammation driven by overexpression of the hypoglycosylated abnormal mucin 1 (MUC1) links inflammatory bowel disease and pancreatitis. Pancreas. 2010;39:510-5.

58. Beatty PL, Plevy SE, Sepulveda AR, et al. Transgenic expression of human MUC1 in IL-10-/- mice accelerates inflammatory bowel disease and progression to colon cancer. J Immunol. 2007;179:735-9.

59. Goto Y, Obata T, Kunisawa J, et al. Innate lymphoid cells regulate intestinal epithelial cell glycosylation. Science. 2014;345:1254009.

60. Neufert C, Pickert G, Zheng Y, et al. Activation of epithelial STAT3 regulates intestinal homeostasis. Cell Cycle. 2010;9:652-5.

61. Fukui H, Sekikawa A, Tanaka H, et al. DMBT1 is a novel gene induced by IL-22 in ulcerative colitis. Inflamm Bowel Dis. 2011;17:1177-88.

62. Lindemans CA, Calafiore M, Mertelsmann AM, et al. Interleukin-22 promotes intestinal-stem-cell-mediated epithelial regeneration. Nature. 2015;528:560-4.

63. Aparicio-Domingo P, Romera-Hernandez M, Karrich JJ, et al. Type 3 innate lymphoid cells maintain intestinal epithelial stem cells after tissue damage. J Exp Med. 2015;212:1783-91.

64. Bootz F, Ziffels B, Neri D. Antibody-based targeted delivery of interleukin-22 promotes rapid clinical recovery in mice with DSS-induced colitis. Inflamm Bowel Dis. 2016;22:2098-105.

65. Monteleone I, Rizzo A, Sarra M, et al. Aryl hydrocarbon receptor-induced signals up-regulate IL-22 production and inhibit inflammation in the gastrointestinal tract. Gastroenterology. 2011;141:237-48.

66. Atreya R, Neurath MF. Current and future targets for mucosal healing in inflammatory bowel disease. Visc Med. 2017;33:82-8.

67. Tsai PY, Zhang B, He WQ, et al. IL-22 upregulates epithelial claudin-2 to drive diarrhea and enteric pathogen clearance. Cell Host Microbe. 2017;21:671-81.

68. Jinnohara T, Kanaya T, Hase K, et al. IL-22BP dictates characteristics of Peyer's patch follicle-associated epithelium for antigen uptake. J Exp Med. 2017;214:1607-18.

69. Gulhane M, Murray L, Lourie R, et al. High fat diets induce colonic epithelial cell stress and inflammation that is reversed by IL-22. Sci Rep. 2016;6:28990.

70. Qiu J, Heller JJ, Guo X, et al. The Aryl hydrocarbon receptor regulates gut immunity through modulation of innate lymphoid cells. Immunity. 2012;36:92-104.

71. Schulz SM, Köhler G, Schütze N, et al. Protective immunity to systemic infection with attenuated Salmonella enterica serovar enteritidis in the absence of IL-12 is associated with IL-23dependent IL-22, but not IL-17. J Immunol. 2008;181:7891-901.

72. De Luca A, Zelante T, D'Angelo C, et al. IL-22 defines a novel immune pathway of antifungal resistance. Mucosal Immunol. 2010;3:361-73. 
73. Kamanaka M, Huber S, Zenewicz LA, et al. Memory/effector (CD45RB(lo)) CD4 T cells are controlled directly by IL-10 and cause IL-22-dependent intestinal pathology. J Exp Med. 2011;208:1027-40.

74. Eken A, Singh AK, Treuting PM, et al. IL-23R+ innate lymphoid cells induce colitis via interleukin-22-dependent mechanism. Mucosal Immunol. 2014;7:143-54.

75. Wolk K, Haugen HS, Xu W, et al. IL-22 and IL-20 are key mediators of the epidermal alterations in psoriasis while IL-17 and IFN-gamma are not. J Mol Med. 2009;87:523-36.

76. Sonnenberg GF, Nair MG, Kirn TJ, et al. Pathological versus protective functions of IL-22 in airway inflammation are regulated by IL-17A. J Exp Med. 2010;207:1293-305.

77. Krausgruber T, Schiering C, Adelmann K, et al. T-bet is a key modulator of IL-23-driven pathogenic CD4(+) T cell responses in the intestine. Nat Commun. 2016;7:11627.

78. Moriwaki K, Balaji S, McQuade T, et al. The necroptosis adaptor RIPK3 promotes injury-induced cytokine expression and tissue repair. Immunity. 2014;41:567-78.

79. Liu X, Wei W, Li X, et al. BMI1 and MEL18 Promote ColitisAssociated Cancer in Mice via REG3B and STAT3. Gastroenterology. 2017 Aug 2. pii: S0016-5085(17)35976-0 (In Press).

80. Xu W, Presnell SR, Parrish-Novak J, et al. A soluble class II cytokine receptor, IL-22RA2, is a naturally occurring IL-22 antagonist. Proc Natl Acad Sci USA. 2001;98:9511-6.

81. Dumoutier L, Lejeune D, Colau D, et al. Cloning and characterization of IL-22 binding protein, a natural antagonist of IL10-related $\mathrm{T}$ cell-derived inducible factor/IL-22. J Immunol. 2001;166:7090-5.

82. Kotenko SV, Izotova LS, Mirochnitchenko OV, et al. Identification, cloning, and characterization of a novel soluble receptor that binds IL-22 and neutralizes its activity. J Immunol. 2001;166:7096-103.

83. Huber S, Gagliani N, Zenewicz LA, et al. IL-22BP is regulated by the inflammasome and modulates tumorigenesis in the intestine. Nature. 2012;491:259-63.

84. Pelczar P, Witkowski M, Perez LG, et al. A pathogenic role for $\mathrm{T}$ cell-derived IL-22BP in inflammatory bowel disease. Science. 2016;354:358-62.

85. Ratsimandresy RA, Indramohan M, Dorfleutner A, et al. The AIM2 inflammasome is a central regulator of intestinal homeostasis through the IL-18/IL-22/STAT3 pathway. Cell Mol Immunol. 2017;14:127-42.

86. Martin JC, Bériou G, Heslan H, et al. Interleukin-22 binding protein (IL-22BP) is constitutively expressed by a subset of conventional dendritic cells and is strongly induced by retinoic acid. Mucosal Immunol. 2014;7:101-13.

87. Martin JC, Bériou G, Heslan M, et al. IL-22BP is produced by eosinophils in human gut and blocks IL-22 protective actions during colitis. Mucosal Immunol. 2016;9:539-49.

88. Lim C, Hong M, Savan R. Human IL-22 binding protein isoforms act as a rheostat for IL-22 signaling. Sci Signal. 2016;9:ra95.

89. Abraham C, Cho JH. Inflammatory bowel disease. N Engl J Med. 2009;361:2066-78.

90. Khor B, Gardet A, Xavier RJ. Genetics and pathogenesis of inflammatory bowel disease. Nature. 2011;474:307-17.

91. Kakuta Y, Kimura T, Negoro K, et al. Increased expression of IL12B mRNA transcribed from the risk haplotype for Crohn's disease is a risk factor for disease relapse in Japanese patients. J Gastroenterol. 2017; doi:10.1007/s00535-017-1322-5 .

92. Glocker EO, Kotlarz D, Boztug K, et al. Inflammatory bowel disease and mutations affecting the interleukin-10 receptor. N Engl J Med. 2009;361:2033-45.

93. Silverberg MS, Cho JH, Rioux JD, et al. Ulcerative colitis-risk loci on chromosomes $1 \mathrm{p} 36$ and $12 \mathrm{q} 15$ found by genome-wide association study. Nat Genet. 2009;41:216-20.

94. Chi HG, Zheng XB, Wu ZG, et al. Association of the interleukin-22 genetic polymorphisms with ulcerative colitis. Diagn Pathol. 2014;9:183.

95. Yamamoto-Furusho JK, Sánchez-Morales GE, García-Rangel $\mathrm{D}$, et al. Genetic polymorphisms of interleukin-22 in patients with ulcerative colitis. Rev Gastroenterol Mex. 2016;81:86-90.

96. Franke A, McGovern DP, Barrett JC, et al. Genome-wide metaanalysis increases to 71 the number of confirmed Crohn's disease susceptibility loci. Nat Genet. 2010;42:1118-25.

97. Kaplan GG, Ng SC. Understanding and preventing the global increase of inflammatory bowel disease. Gastroenterology. 2017;152:313-21.

98. Colombel JF, Watson AJ, Neurath MF. The 10 remaining mysteries of inflammatory bowel disease. Gut. 2008;57:429-33.

99. Monteleone I, Pallone F, Monteleone G. Aryl hydrocarbon receptor and colitis. Semin Immunopathol. 2013;35:671-5.

100. Iqbal J, Sun L, Cao J, et al. Smoke carcinogens cause bone loss through the aryl hydrocarbon receptor and induction of Cyp1 enzymes. Proc Natl Acad Sci USA. 2013;110:11115-20.

101. Xue J, Zhao Q, Sharma V, et al. Aryl hydrocarbon receptor ligands in cigarette smoke induce production of interleukin-22 to promote pancreatic fibrosis in models of chronic pancreatitis. Gastroenterology. 2016;151:1206-17.

102. Zelante T, Iannitti RG, Cunha C, et al. Tryptophan catabolites from microbiota engage aryl hydrocarbon receptor and balance mucosal reactivity via interleukin-22. Immunity. 2013;39:372-85.

103. Lamas B, Richard ML, Leducq V, et al. CARD9 impacts colitis by altering gut microbiota metabolism of tryptophan into aryl hydrocarbon receptor ligands. Nat Med. 2016;22:598-605.

104. Sugimoto S, Naganuma M, Kanai T. Indole compounds may be promising medicines for ulcerative colitis. J Gastroenterol. 2016;51:853-61.

105. Sugimoto S, Naganuma M, Kiyohara $\mathrm{H}$, et al. Clinical efficacy and safety of oral qing-dai in patients with ulcerative colitis: a single-center open-label prospective study. Digestion. 2016;93:193-201.

106. Kawai S, Iijima H, Shinzaki S, et al. Indigo naturalis ameliorates murine dextran sodium sulfate-induced colitis via aryl hydrocarbon receptor activation. J Gastroenterol. 2017;52:904-19.

107. Chebli K, Papon L, Paul C, et al. The anti-HIV candidate Abx464 dampens intestinal inflammation by triggering Il-22 production in activated macrophages. Sci Rep. 2017;7:4860.

108. Low D, Mino-Kenudson M, Mizoguchi E. Recent advancement in understanding colitis-associated tumorigenesis. Inflamm Bowel Dis. 2014;20:2115-23.

109. Bollrath J, Phesse TJ, von Burstin VA, et al. gp130-mediated Stat 3 activation in enterocytes regulates cell survival and cellcycle progression during colitis-associated tumorigenesis. Cancer Cell. 2009;15:91-102. 